\title{
Coordination Control Strategy for Compound Fault of MMC-HVDC
}

\author{
Ming Guang Zhang ${ }^{1}$, Zhao Yu Zhang ${ }^{1, a}$, Li Jie Qiü ${ }^{2}$ and Xi Chen ${ }^{1}$ \\ ${ }^{1}$ School of Electrical and Information Engineering, Lanzhou University of Technology, Lanzhou, China \\ ${ }^{2}$ Lanzhou Petrochemical Company Power Plant, Lanzhou, China
}

\begin{abstract}
Single-line to ground fault of DC side and sub-module fault are typical faults of MMC-HVDC. When each of the above faults occurs, the system will give a signal for circuit-breaker releasing, this will result in interruption of power delivery, the stability of the system is greatly reduced. When these two faults occur simultaneously, research on control strategy for compound fault will help to improve the reliability of the system. While single-line to ground fault of DC side happens, only the electric potential auxiliary point of DC side is changed, system's power transport normally. When sub-module is fault, redundancy fault-tolerated control strategy is presented, which replace the failed sub-modules with equal number of redundant sub-modules, it can restrain the fluctuation of direct current. A double terminals and 21 voltage-level MMC-HVDC system simulation model is set up in PSCAD/EMTDC. From the computation and simulation results, it is concluded that the proposed control strategy is correct for above compound fault, it can achieve rapid recovery after faults, effectively improve fault tolerance of the system, develop the stability and reliability of the system.
\end{abstract}

\section{Introduction}

Modular Multilevel Converter is a VSC topology proposed by Marquardt and Lesnicar of the University of the Bundeswehr Munich in 2002, And researcher of the power electronics laboratory of the school developed a prototype in 2004 [1]. Compared to the traditional twolevel or three-level voltage source converter topology, MMC has obvious advantages such as reducing switching losses, upgrading capacity, electromagnetic compatibility, fault management, etc[2-3]. TBC (Trans Bay Cable) project of the United States, Nanhui wind farm demonstration project of China's Shanghai, Nan'ao threeterminal HVDC flexible engineering(the world's first multi-terminal VSC engineering)has been put into operation in the MMC-HVDC projects[4].

With the growing shortage of fossil fuels, and the use of fossil fuels brings problems such as environmental pollution, the concerns must be transferred to the development and utilization of clean renewable energy. Liu Zhenya, chairman of the China State Grid Corp, in his book, "Global Energy Internet," a profound point is proposed: The alternative of clean energy and electric energy will become the inevitable trend of global energy development. MMC-HVDC is more flexible, and it has the technology features of economic and environmental protection. According to the operational status of the onsite project, MMC is suitable for grid-connected of the renewable energy and distributed generation, and its research will become a hot spot. At home and abroad, the control and protection research of MMC-HVDC is mostly aimed at single fault modeling and simulation analysis of two-terminal or multi-terminal system, in addition, DC bus fault and sub-module fault is the typical fault of MMC-HVDC. The DC side bus fault is divided into single pole ground fault, the pole-to-pole short circuit fault and the break line fault [5]. The reference[6] analyzes three kinds of DC-side faults qualitatively for MMC-HVDC, designs their respective control and protection strategies. The reference [7] establishes a circuit model under pole-to-pole short circuit fault, a detailed analysis of fault characteristic is done for it. In addition, the reference carries out overcurrent stress analysis, provides the basis for designing the electrical element of sub-module. The reference [5] analyzes the effects of three kinds of DC-side faults on the system, presents the corresponding control protection strategies and protection timing sequence for MTDC technology based modular multi-level converter. Tang, $\mathrm{Xu}$, and $\mathrm{Zhou}$ (2014) analyzes the transient stability of three MMCHVDC topology under DC-side fault, the result of analysis and simulation shows that LCC-D-MMC-HVDC topology performance is the most superior[8]. Tang and $\mathrm{Xu}$ (2014)analyzes the fault clearance capability when a LCC and MMC hybrid HVDC topology with DC line fault, It pointed out that the DC line fault can be cleared by delaying the trigger angle of LCC and changing high power diode which installed at the overhead line close to the inverse[9]. Sub-module faults include power electronic devices (IGBT or with anti-parallel diode) fault, capacitor fault and trigger signal fault [10]. The reference[11-12] pointed out that during the switching of

\footnotetext{
a Corresponding author: zzy411010283@163.com
} 
sub-module, the maximum current flowing through the sub-module is much higher than RMS, and the change rate of the current relatively high. The reference [13] points out a single sub-module fault will lead to DC voltage and current's oscillations, meanwhile proposes sub-module fault redundancy protection method. Hu et al.(2013) analyzes and compares the advantages and disadvantages of three sub-module redundant faulttolerant solutions, basic mathematical model derived from MMC running in redundant state. On the basis of mathematical expression derived from bridge-arm energy, proposes redundant fault-tolerant solution to restrain direct current fluctuations[10]. This paper introduces the sub-module redundancy protection method of the reference[13], taking into account that when the monopolar grounding fault occurs, the system can still transmit power normally, if the sub-module fault occurs at same time, research in this compound fault is necessary.

\section{Structure and operation mechanism of MMC-HVDC}

\subsection{Topology of MMC-HVDC}

MMC-HVDC's one-terminal topology is shown in Figure 1. Each phase has two bridge-arms, every bridge-arm consists of several sub-modules(SM) and with a serial reactors $L_{s}$. DC side voltage between the two poles is $U_{d}$, positive voltage is $U_{d} / 2$, negative voltage is $-U_{d} / 2, i_{p j}(j=a, b, c)$ is the current of each upper bridgearm, $i_{n j}(j=a, b, c)$ is the current of each lower bridgearm, $v_{a}, v_{b}, v_{c}$ and $i_{a}, i_{b}, i_{c}$ are voltage and current at the AC side' outlet of converter. The structure of a submodule is shown in Figure 2, it is consisted by two IGBT and corresponding anti-parallel diodes, then, with a shunt capacitors.

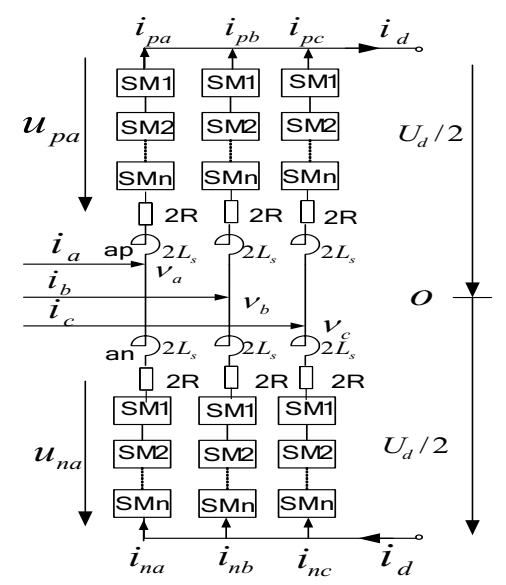

Figure 1. MMC-HVDC one-end topology.

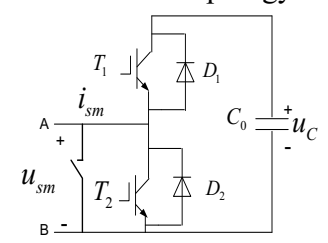

Figure 2. The sub-module's topology.

\subsection{Mathematical model of MMC-HVDC}

According to Kirchhoff's current law, current of phase $k(k=a, b, c)$ can be expressed as $i_{k}=i_{p k}+i_{n k}$, application of Kirchhoff' s voltage law.

$$
\begin{aligned}
& v_{k}-\left(\frac{U_{d}}{2}-u_{p k}\right)=2 L_{s} \frac{d i_{p k}}{d t}+2 R i_{p k} \\
& v_{k}-\left(u_{n k}-\frac{U_{d}}{2}\right)=2 L_{s} \frac{d i_{n k}}{d t}+2 R i_{n k}
\end{aligned}
$$

(1) $+(2)$, considering $u_{k}=\left(u_{n k}-u_{p k}\right) / 2$,

$$
v_{k}-u_{k}=L_{s} \frac{d i_{k}}{d t}+R i_{k}
$$

The three-phase form of formula (3) is:

$$
\left\{\begin{array}{l}
L_{s} \frac{d i_{a}(t)}{d t}+R i_{a}(t)=v_{a}(t)-u_{a}(t) \\
L_{s} \frac{d i_{b}(t)}{d t}+R i_{b}(t)=v_{b}(t)-u_{b}(t) \\
L_{s} \frac{d i_{c}(t)}{d t}+R i_{c}(t)=v_{c}(t)-u_{c}(t)
\end{array}\right.
$$

For use of converter transformer, it will block the path of zero sequence current, in asymmetrical grid fault condition, it will contain negative sequence component, same as formula (4).

\subsection{Control strategy of MMC-HVDC}

Converter's control use DQ decoupling control strategy, state variable is $i_{d}{ }^{+}$and $i_{q}^{+}$, disturbance component is $v_{d}^{+}$ and $v_{q}{ }^{+}$, input variable is $u_{d}{ }^{+}$and $u_{q}{ }^{+} \cdot i_{d}{ }^{+^{*}}, i_{q}^{+^{*}}, i_{d}{ }^{-*} i_{q}{ }^{-*}$ are given reference values. Introducing voltage coupling compensation items $\omega L_{s} i_{d}^{+}$and $\omega L_{s} i_{q}^{+}$, proportionalplus-integral control, then, input value of positive sequence current controller is shown in formula (5) and (6):

$$
\begin{aligned}
& u_{d}^{+^{*}}=v_{d}^{+}+\omega L_{s} i_{q}^{+}-\left[k_{p 1}\left(i_{d}^{+^{*}}-i_{d}^{+}\right)+k_{i 1} \int\left(i_{d}^{+^{*}}-i_{d}^{+}\right) d t\right] \\
& u_{q}^{+^{*}}=v_{q}^{+}-\omega L_{s} i_{d}^{+}-\left[k_{p 2}\left(i_{q}^{+^{*}}-i_{q}^{+}\right)+k_{i 2} \int\left(i_{q}^{+^{*}}-i_{q}^{+}\right) d t\right]
\end{aligned}
$$

Similar to positive sequence parameters, input value of negative sequence current controller is shown in formula (7) and (8):

$$
\begin{aligned}
& u_{d}^{{ }^{*}}=v_{d}^{-}-\omega L_{s} i_{q}^{-}-\left[k_{p 3}\left(i_{d}^{-*}-i_{d}^{-}\right)+k_{i 3} \int\left(i_{d}^{{ }^{*}}-i_{d}^{-}\right) d t\right] \\
& u_{q}^{{ }^{*}}=v_{q}^{-}+\omega L_{s} i_{d}^{-}-\left[k_{p 4}\left(i_{q}^{-*}-i_{q}^{-}\right)+k_{i 4} \int\left(i_{q}^{-^{*}}-i_{q}^{-}\right) d t\right]
\end{aligned}
$$

we can get the dynamic expression of positive sequence d-q axis current component, which has been decoupled. It is shown in formula(9):

$$
\left\{\begin{array}{l}
L_{s} \frac{d i_{d}{ }^{+}(t)}{d t}+R i_{d}{ }^{+}(t)=k_{p 1}\left(i_{d}^{+^{*}}-i_{d}^{+}\right)+k_{i 1} \int\left(i_{d}^{+^{*}}-i_{d}^{+}\right) d t \\
L_{s} \frac{d i_{q}^{+}(t)}{d t}+R i_{q}^{+}(t)=k_{p 2}\left(i_{q}^{+^{*}}-i_{q}^{+}\right)+k_{i 2} \int\left(i_{q}^{+^{*}}-i_{q}^{+}\right) d t
\end{array}\right.
$$

We can get the dynamic expression of negative sequence $\mathrm{d}-\mathrm{q}$ axis current component similarly, they all make the coupling system decoupled. The control block diagram of positive sequence inner current decoupling controller is as follows[14]. 


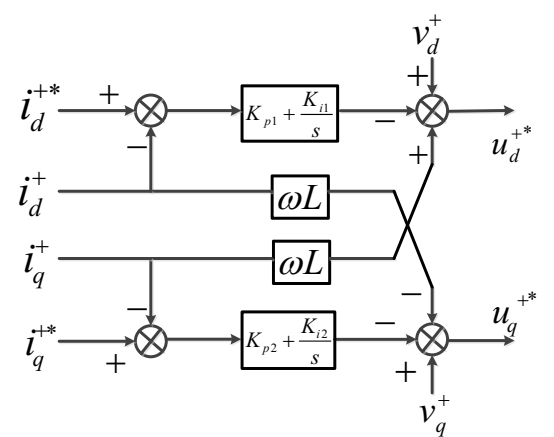

Figure 3. Structure of positive sequence inner current decoupling controller.

Modulation strategy using nearest level modulation(NLM)[15], Capacitor voltage balance control strategy is to monitor the capacitor voltage, then determine putting into or removing sub-modules according to capacitor voltage value[16].

\section{Faults and its control strategy analysis}

\subsection{Control strategy of MMC-HVDC}

DC Pole-to-Pole fault and break line fault are generally permanent fault, when detecting these two faults, the inverters must be closed, and the AC circuit breaker tripped, out of operation. When use overhead line as the DC transmission line, monopolar grounding fault has the maximum probability of occurrence, and it is usually a temporary fault. To prevent clamp capacitor will discharge through the ground and have a greater surge current, DC side use the structure of two large grounding resistance, the single-phase structure is shown in Figure 4. Firstly, this structure can clamp the voltage of pole-topole, secondly, it can provide a electric potential auxiliary point for positive and negative bus.

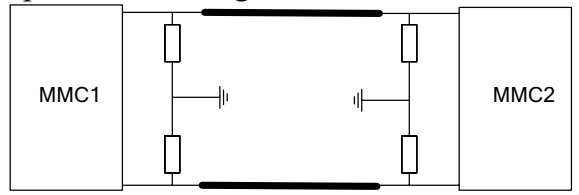

a) During Normal Operation

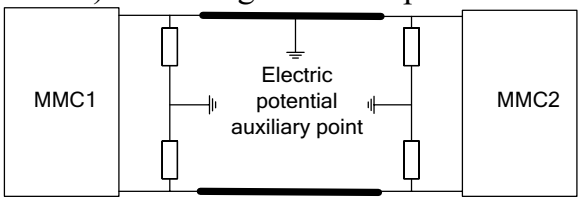

b) Monopolar Grounding Fault

Figure 4. MMC-HVDC single-phase structure diagram.

When monopolar grounding fault occurs at positive pole, positive voltage $U_{+}=U_{d} / 2$ becomes zero, due to the large clamp resistance, negative voltage becomes twice of the original $\left(U_{-}=-U_{d}\right)$, however, the voltage $U_{d}$ between two poles is constant, therefore, the system can transmit power continuously, and due to the large resistance, the capacitor in operating sub-module hasn't discharge path, capacitor voltage remains stable, this is beneficial to the fast recovery of system under the fault is cleared. All this characteristic is shown in Figure $5-6$.

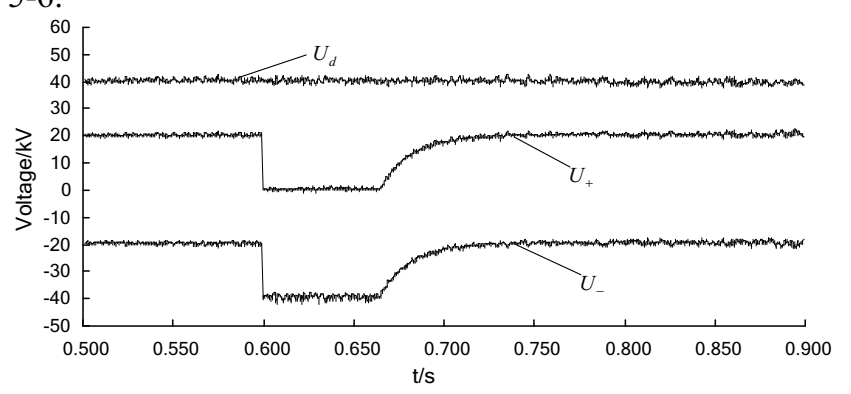

Figure 5. DC side voltage under the situation of monopolar grounding fault.

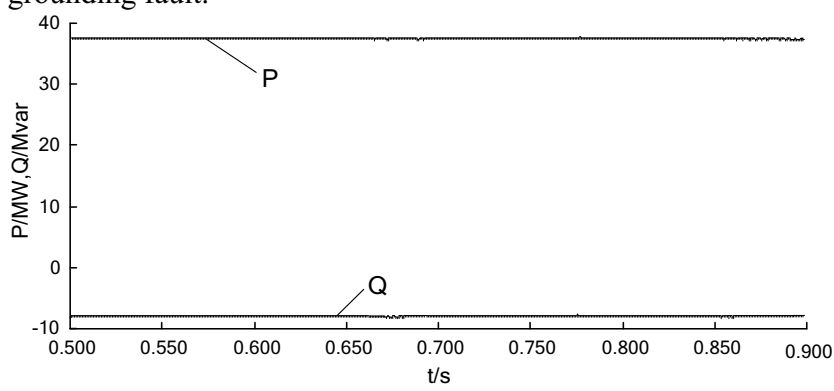

Figure 6. Active and reactive power at rectifier.

\subsection{MMC-HVDC Sub-module fault}

While monitoring the sub-module fault, we should bypass the faulted sub-modules. at this time, the converter station works in asymmetrical status, voltage deviation of fault phase and another two phases increases, this would increase the internal circulation. DC voltage and current, bridge-arm current will start to oscillate, it will impact the rest of normal working sub-modules. Without quick action, this situation will eventually make the system out of operation, but if after bypassing fault sub-modules, same amount of redundant sub-modules are input, through a process to charge the capacitor, the system can transmit power normally. However, bypassing the fault sub-modules, inputting standby redundancy sub-module and charging the capacitor to reach equilibrium, this process will take some time. During this time, to minimize fluctuations in voltage and current, bridge-arm energy of each phase should be balanced. Order the number of sub-module on each phase before the fault occurs totally is $N$, number of fault sub-module is $N_{f}$, Pre-fault voltage across each sub-module is $U_{c}$, voltage across each sub-module after the fault is $U_{f}$, then, the bridge-arm energy before and after fault is:

$$
\begin{gathered}
W=\frac{1}{2} \frac{C}{N}\left(N U_{c}\right)^{2} \\
W_{f}=\frac{1}{2} \frac{C}{N-N_{f}}\left[\left(N-N_{f}\right) U_{f}\right]^{2}
\end{gathered}
$$

$W=W_{f}$, then $N U_{c}{ }^{2}=\left(N-N_{f}\right) U_{f}{ }^{2}$, thereby pushed out: 


$$
\sqrt{\frac{N}{N-N_{f}}} U_{c}=U_{f}
$$

And considering $U_{c}=U_{d} / N$, then:

$$
\sqrt{\frac{1}{N\left(N-N_{f}\right)}} U_{d}=U_{f}
$$

With this control strategy can avoid large fluctuations, smooth DC voltage waveform. Combining redundant sub-module, it will be a smooth transition to the original operating state.

\section{Compound fault and its simulation}

Establish the model of two-terminal MMC-HVDC system in PSCAD/EMTDC, the parameters is show in Table 1, the primary side of converter transformer adopts star type connection, and the secondary side adopts delta connection. Reference direction of active and reactive power is from the AC side to the DC side, set value of rectifier for D-Q decoupling control is: $\mathrm{DC}$ voltage $=40 \mathrm{kV}$, reactive power $=-8 \mathrm{Mvar}$, active power at inverter side $=36 \mathrm{MW}$, reactive power $=8 \mathrm{Mvar}$.

Table 1. Simulation parameters.

\begin{tabular}{|c|c|c|}
\hline Variables & Symbol & Value \\
\hline Rated AC voltage & $\mathrm{U}_{\mathrm{s}}$ & $10 \mathrm{kV}$ \\
\hline AC reactor & $\mathrm{L}$ & $1.5 \mathrm{mH}$ \\
\hline AC circuit resistance & $\mathrm{R}$ & $0.2 \mathrm{ohm}$ \\
\hline $\begin{array}{c}\text { Rated capacity of converter } \\
\text { transformer }\end{array}$ & - & $40 \mathrm{MVA}$ \\
\hline Converter transformer ratio & - & $10 \mathrm{kV} / 23 \mathrm{kV}$ \\
\hline Rated frequency & $\mathrm{f}$ & $50 \mathrm{~Hz}$ \\
\hline Rated DC voltage & $\mathrm{U}_{\mathrm{d}}$ & $40 \mathrm{kV}$ \\
\hline Bridge-arm buffer reactance & $\mathrm{L}_{\mathrm{s}}$ & $8 \mathrm{mH}$ \\
\hline Number of SM of single bridge-arm & $\mathrm{N}$ & 20 \\
\hline $\begin{array}{c}\text { The number of redundant sub- } \\
\text { module at each bridge-arm }\end{array}$ & $\mathrm{N}_{\mathrm{r}}$ & 1 \\
\hline Number of fault SM at bridge-arm & $\mathrm{N}_{\mathrm{f}}$ & 1 \\
\hline Capacitor voltage of SM & $\mathrm{U}_{\mathrm{c}}$ & $2 \mathrm{kV}$ \\
\hline Capacitance value of SM & $\mathrm{C}$ & $9 \mathrm{mF}$ \\
\hline
\end{tabular}

The settings of rectifier fault protection sequence are as follows: at $0.6 \mathrm{~s}$, the monopolar grounding fault at positive pole in DC side is switched in, $0.605 \mathrm{~s}$, the submodule fault occurs, $0.61 \mathrm{~s}$, put redundant sub-module into operation, entire fault persists $0.065 \mathrm{~s}$.

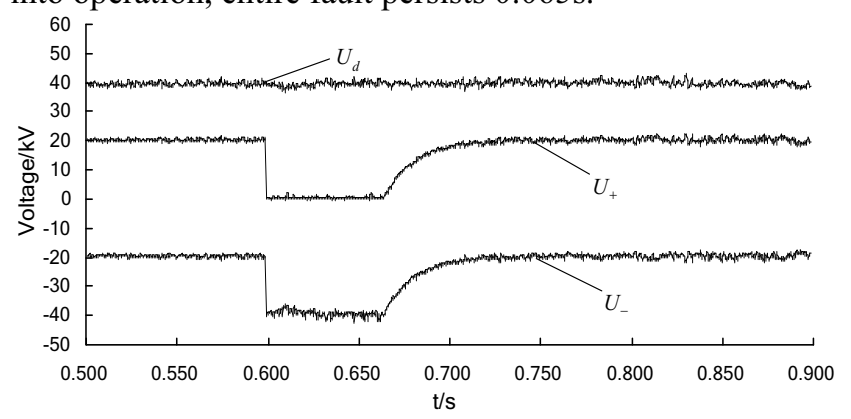

Figure 7. DC voltage when compound fault occurs.

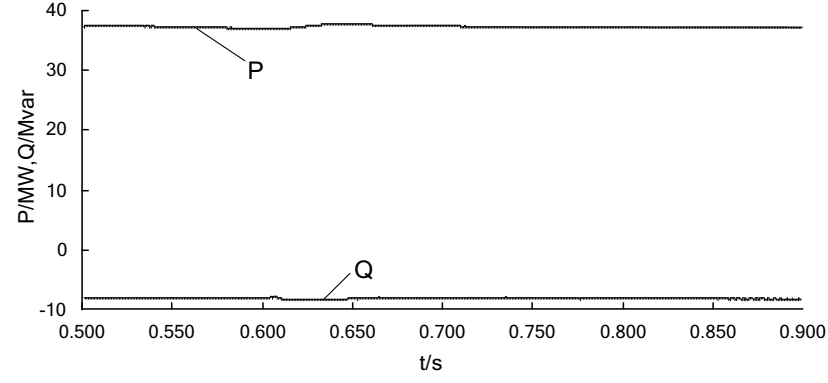

Figure 8. Active and reactive power at the rectifier when compound fault occurs.

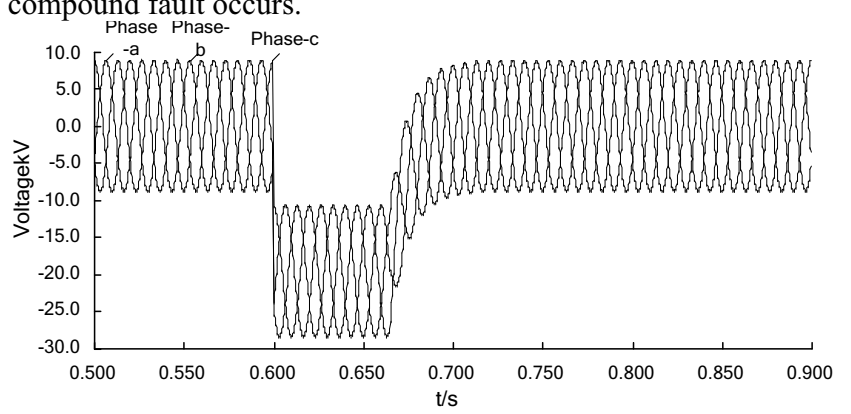

Figure 9. The voltage of converter station at ac side.

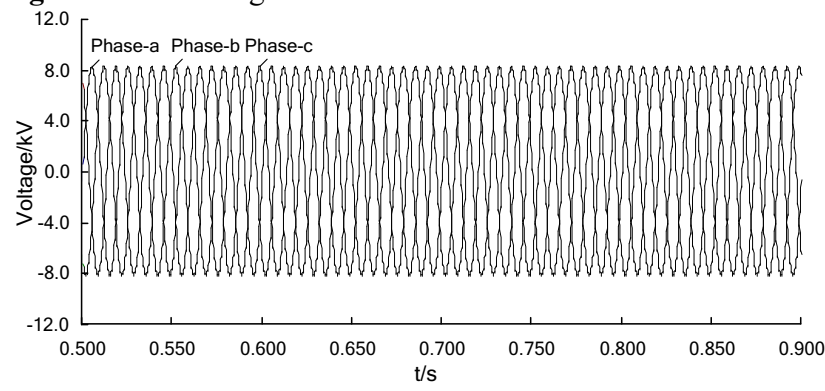

a) The voltage of converter transformer in its AC side.

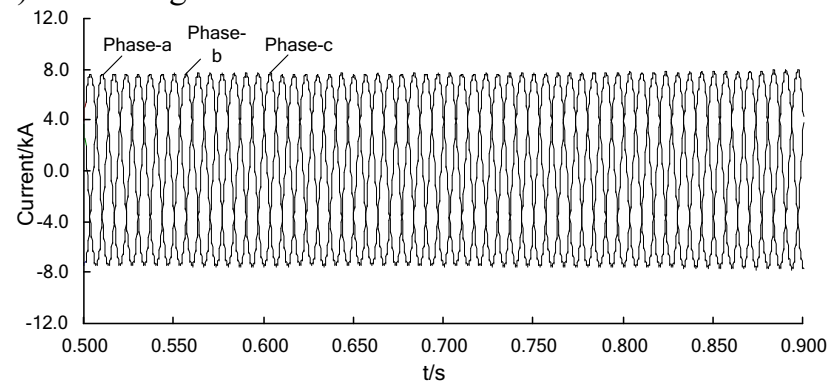

b) The current of converter transformer in its AC side.

Figure 10. The AC waveform when compound fault occurs.

As can be seen from the above simulation waveform, DC voltage and its active and reactive power shown in Figure 7 and Figure 8. DC voltage waveform is similar to the situation of monopolar grounding fault. At $0.61 \mathrm{~s}$, due to inputting the redundant sub-modules, after a brief shock, the system resume normal operation. In the fault and its recovery process, the active and reactive power will fluctuate, but the fluctuation will limit within the allowable range. Figure 9 is the voltage waveform at converter station AC outlet, when monopolar grounding fault occurs, because positive pole is grounding, positive voltage is zero, electric potential auxiliary point is changed, voltage will drop a original positive voltage which is $20 \mathrm{kV}$, so we need to improve the insulation level of the AC bus. Voltage and current of line-side 
converter transformer is shown in Figure 10, the fault basically has no effect on the voltage and current at converter transformer of line-side.

\section{Conclusion}

As can be seen from the simulation waveform, fault characteristics are as follows:

1) Coordination control strategy is not only good for voltage balance control, but also for quickly recovery after fault. As the AC system, when monopolar grounding fault occurs, if meet the insulation requirement, MMC-HVDC system will allow transient operation.

2) During the charging time of the redundant modules, the redundancy fault-tolerated control strategy based on energy balance of bridge-arms can reduce the voltage and current fluctuation.

3) On the basis of the monopolar grounding fault protection and control of sub-module fault, compound fault protection can be achieved easily, there is no need to add additional protective measures.

From the above, the coordination control strategy for compound fault can improve the reliability and fault tolerance of MMC-HVDC system. The control strategy is feasible, simulation results verify it.

\section{Acknowledgements}

The work is supported in part by the National Science Foundation of China under grant No.51567016.

\section{References}

1. R. Marquardt and A. Lesnicar, "New Concept for High Voltage-Modular Multilevel Converter", Proceedings of the 2004 IEEE Power Electronics Specialists Conference, Aachen, Germany, (2004) June 25-26.

2. M. Hagiwara, K. Nishimura and H. Akagi, "A Medium-voltage Motor Drive with a Modular Multilevel PWM Inverter", IEEE Trans on Industrial Electronics, vol. 25, no. 7, (2010), pp. 1786-1799.

3. J. Dorn, H. Huang and D. Retzmann, "A New Multilevel Voltage-sourced Converter Topology for HVDC Applications", CIGRE Session: International Council on Large Electric Systems, Paris, France (2008).

4. C. Y. Zhao, T. Li, L. J. Yu, Y. Huang, L. F. Li and X. L. Li, "DC Pole-to-ground Fault Characteristic Analysis and Converter Fault Recovery Strategy of MMC-HVDC", Proceedings of the CSEE, vol. 34, no. 21, (2014), pp. 3518-3526.

5. X. N. Zhang, C. Y. Zhao and H. Pang. "A Control and Protection Scheme of Multi-terminal DC Transmission System Based on MMC for DC Line Fault", Automation of Electric Power System, vol. 37, no. 15, (2013), pp. 140-145.

6. C. Y. Zhao, X. F. Chen, C. G. Cao and H. B. Jing, "Control and Protection Strategies for MMC-HVDC under Faults", Automation of Electric Power Systems, vol. 35, no. 23, (2011), pp. 82-87.

7. S. S. Wang, X. X. Zhou, G. F. Tang, Z. Y. He, L. T. Teng and H. L. Bao, "Analysis of Submodule Overcurrent Caused by DC Pole-to-pole Fault in Modular Multilevel Converter HVDC System", Proceedings of the CSEE, vol. 31, no. 1, (2011), pp. 1-7.

8. G. Tang, Z. Xu and Y. Z. Zhou, "Impacts of Three MMC-HVDC Configurations on AC System Stability Under DC Line Faults", IEEE TRANSACTIONS ON POWER SYSTEMS, vol. 29, no. 6, (2014), pp. 3030-3040.

9. G. Tang and Z. Xu, "A $\mathrm{LCC}$ and MMC Hybrid HVDC Topology with DC Line Fault Clearance Capability", INTERNATIONAL JOURNAL OF ELECTRICAL POWER \& ENERGY SYSTEMS, vol. 62, no. 11, (2014), pp. 419-428.

10. P. F. Hu, D. Z. Jiang, Y. B. Zhou, Z. Y. Lin, Y. Q. Liang and J. Guo, "Redundancy Fault-tolerated Control Strategy for Sub-module Faults of Modular Multilevel Converters", Automation of Electric Power Systems, vol. 37, no. 15, (2013), pp. 66-70.

11. L. G. Franquelo, J. Rodriguez, J. I. Leon, S. Kouro and R. Portillo, "The Age of Multi-level Converters Arrives", IEEE Industrial Electronics Magazine, vol. 2, no. 2, (2008), pp. 28-39.

12. J. Dorn, H. Huang and D. Retzmann, "Novel Voltage Source Converters for HVDC and FACTS Applications", CIGRE International Symposium Conference, Osaka, Japan, (2007) pp. 1-8.

13. M. Y. Guan and Z. Xu, "Redundancy Protection for Sub-module Faults in Modular Multilevel Converter", Automation of Electric Power Systems, vol. 35, no. 16, (2011), pp. 94-99.

14. M. Y. Guan and Z. Xu, "Modeling and Control of Modular Multilevel Converter-based HVDC Systems under Unbalanced Grid Conditions", IEEE Transactions on Power Electronics, vol. 27, no. 12, (2012), pp. 4858-4867.

15. M. Y. Guan, Z. Xu, Q. R. Tu and W. Y. Pan, "Nearest Level Modulation for Modular Multilevel Converters in HVDC Transmission", Automation of Electric Power Systems, vol. 34, no. 2, (2010), pp. 48-52.

16. M. Y. Guan, Z. Xu, “Optimized Capacitor Voltage Balancing Control for Modular Multilevel Converter Based VSC-HVDC System", Proceedings of the CSEE, vol. 31, no. 12, (2011), pp. 9-14. 